\title{
Detecção de anticorpos para Paracoccidioides brasiliensis em cavalos da região norte do Estado do Paraná
}

\author{
Detection of antibodies to Paracoccidioides brasiliensis in horses \\ from northern Region of Paraná State
}

\author{
Andréia Corrêa Corte ${ }^{1}$; Eiko Nakagawa Itano ${ }^{2}$; Roberta Lemos Freire ${ }^{3}$; \\ Zoilo Pires de Camargo ${ }^{4}$; Mario Augusto $\mathrm{Ono}^{5 *}$
}

\begin{abstract}
Resumo
A paracoccidioidomicose, causada pelo fungo dimórfico Paracoccidioides brasiliensis, é a micose sistêmica de maior prevalência em humanos na América Latina. A paracoccidioidomicose afeta principalmente trabalhadores rurais do sexo masculino, provocando lesões granulomatosas em órgãos como pulmões, fígado e baço. A participação de outras espécies de animais na eco-epidemiologia do fungo não é bem compreendida. Este trabalho teve como objetivo avaliar a infecção por $P$. brasiliensis em cavalos da Região Norte do Estado do Paraná. Foram analisadas 100 amostras de soros de cavalos por ELISA e por Imunodifusão em gel de agar, utilizando como antígenos a gp43 e o exoantígeno de $P$. brasiliensis, respectivamente. A soropositividade observada foi de $30 \%$ por ELISA enquanto que por imunodifusão todos os soros foram negativos. Os resultados obtidos sugerem que cavalos podem ser indicadores da presença do fungo no meio ambiente.
\end{abstract}

Palavras-chave: Paracoccidioides brasiliensis, cavalos, epidemiologia

\begin{abstract}
Paracoccidioidomycosis, caused by the dimorphic fungus Paracoccidioides brasiliensis, is the most prevalent human systemic mycosis in Latin America. Paracoccidioidomycosis affects mainly male rural workers, causing granulomatous lesions in organs such as lungs, liver and spleen. The participation of other animal species in the fungus eco-epidemiology in not well understood. The aim of this study was to evaluate the infection by P. brasiliensis in horses from the Northern Region of Paraná State. The serum samples from 100 horses were assayed by ELISA and Immunodiffusion test, using gp43 and exoantigen as antigens, respectively. A seropositivity of $30 \%$ was observed by ELISA test, although all samples were negative by immunodiffusion test. These results suggest that horses can be indicator of fungus presence in the ambient.
\end{abstract}

Key words: Paracoccidioides brasiliensis, horses, epidemiology

\footnotetext{
1 Biomédica, Mestre em Patologia Experimental, Universidade Estadual de Londrina.

2 Docente do Depto. de Ciências Patológicas, Universidade Estadual de Londrina.

3 Docente do Depto. de Medicina Veterinária Preventiva, Universidade Estadual de Londrina, Londrina, PR.

4 Depto. de Microbiologia, Imunologia e Parasitologia, UNIFESP, São Paulo, SP.

5 Docente do Depto. de Ciências Patológicas, Universidade Estadual de Londrina. E-mail: marioono@uel.br

* Autor para correspondência
} 


\section{Introdução}

O fungo Paracoccidioides brasiliensis, é o agente etiológico da paracoccidioidomicose (PCM), a micose sistêmica humana mais prevalente na América Latina. No Brasil, os Estados de São Paulo, Paraná, Minas Gerais, Rio Grande do Sul e Rio de Janeiro apresentam o maior número de casos registrados em humanos (COUTINHO et al., 2002). O fungo cresce na forma de micélio a $25^{\circ} \mathrm{C}$; e apresenta-se na forma de levedura no organismo humano ou in vitro a $37^{\circ} \mathrm{C}$ (BRUMMER; CASTANEDA; RESTREPO, 1993).

A infecção provavelmente ocorre pela inalação de propágulos do fungo provenientes do solo e para que haja o progresso da doença, é necessária a conversão desses propágulos para a forma de levedura (BORGES-WALMSLEY et al., 2002; FRANCO et al., 1987 ). O primeiro órgão a ser afetado é o pulmão, podendo haver disseminação para outros órgãos e tecidos como fígado, baço, linfonodos, pele e mucosas (BRUMMER; CASTANEDA; RESTREPO, 1993; SCULLY; ALMEIDA, 1992).

A PCM pode ser classificada em PCM-infecção e PCM-doença (FRANCO et al., 1987). A PCMinfecção atinge indivíduos aparentemente sadios (independente do sexo), que residem ou residiram em zona endêmica e apresentam reação positiva para antígenos de $P$. brasiliensis em teste intradérmico ou sorológico, mas não desenvolvem a doença. A forma crônica da PCM-doença ocorre preferencialmente em indivíduos do sexo masculino, trabalhadores rurais, com idade entre 30 a 50 anos, enquanto que as formas aguda e sub-aguda são menos freqüentes e ocorrem em jovens, independentemente do sexo (BLOTTA; CAMARGO, 1993; LONDERO; RAMOS, 1972; McEWEN et al., 1995).

Muitos progressos estão sendo obtidos no estudo sobre a patogenia e o diagnóstico da doença, mas pouco se sabe sobre a ecologia do fungo. Desde o primeiro relato da doença, há um século (LUTZ, 1908), poucos isolamentos de P. brasiliensis foram obtidos do solo (ALBORNOZ, 1971; SILVA-
VERGARA et al., 1998) ou de animais como tatus (BAGAGLI et al., 1998; NAIFF et al., 1986 et al., 1998), morcegos (GROSE; TAMSITT, 1965) e cães (FARIAS et al., 2005).

A participação de outras espécies animais, com exceção do tatu (Dasypus novemcinctus), no ciclo biológico de $P$. brasiliensis ainda não está esclarecida. A infecção por $P$. brasiliensis tem sido demonstrada em diferentes espécies de animais domésticos como cães, bovinos, eqüinos e silvestres como macacos e felinos (CORTE et al., 2007; COSTA; FAVA NETTO, 1978; MÓS; FAVA NETTO, 1974; ONO et al., 2001; SILVEIRA et al., 2006, 2008).

Considerando a escassez de dados sobre a ecoepidemiologia da paracoccidioidomicose, este estudo teve como objetivo avaliar a infecção por $P$. brasiliensis em cavalos da Região Norte do Estado do Paraná.

\section{Material e Métodos}

\section{Animais}

As amostras de sangue foram coletadas por meio de punção da veia jugular, de 100 cavalos (53 machos e 47 fêmeas), provenientes da Região Norte do Paraná. Essa Região apresenta altitudes entre 435 a $850 \mathrm{~m}$, clima subtropical úmido mesotérmico, verões quentes e geadas pouco freqüentes, com tendência de concentração das chuvas nos meses de verão, sem estação seca definida. A média das temperaturas dos meses mais quentes é superior a $22^{\circ} \mathrm{C}$, e a dos meses mais frios é inferior a $18^{\circ} \mathrm{C}$. A faixa etária dos animais variou de um a dezesseis anos. As amostras de soro foram armazenadas a -20 ${ }^{\circ} \mathrm{C}$ até o momento da análise.

\section{Antígenos de $P$. brasiliensis}

\section{Obtenção de exoantígeno}

O isolado de $P$. brasiliensis B-339 foi incubado por 3-4 dias a $35^{\circ} \mathrm{C}$, em tubos de ágar Sabouraud, 
e transferido para meio de neopeptona e incubado a $35^{\circ} \mathrm{C}$. Após três dias, esse pré-inóculo foi transferido para um frasco contendo o mesmo meio e incubado por sete dias sob agitação. A cultura foi inativada por adição de timerosal $(0,05 \%)$, incubada por 18 horas e filtrada. O filtrado bruto foi concentrado a vácuo, dialisado por 48 horas em água destilada e submetido à liofilização (CAMARGO et al., 1988).

\section{Antígeno gp43}

O antígeno gp43 foi obtido a partir do exoantígeno, utilizando uma coluna cromatográfica de afinidade (Affi-Gel 10, BioRad, Hercules, CA, USA), ligado com anticorpo monoclonal antigp43 (SARAIVA et al., 1996). A concentração da proteína foi determinada pelo método de Bradford (BRADFORD, 1976).

\section{ELISA com gp43}

Microplacas de poliestireno de 96 cavidades (Corning Costar Corporation, Corning, NY, USA) foram sensibilizadas com $100 \mu \mathrm{L}$ de gp43 em tampão carbonato $(\mathrm{pH} 9,6)$ e incubadas a $4^{\circ} \mathrm{C}$ durante 18 horas. As placas foram lavadas com tampão fosfato salina (PBS) com Tween 20 (T) e bloqueadas com PBS-leite 1\% (leite desnatado em PBS) por 30 minutos. A seguir a placa foi lavada três vezes com PBS-T e incubada durante uma hora a $25^{\circ} \mathrm{C}$ com os soros diluídos 1:100 em PBS-leite $1 \%$. Foram adicionados em cada poço $100 \mu \mathrm{L}$ de proteína G-peroxidase (Biorad, Hercules, CA, USA), seguido de incubação por uma hora a $25^{\circ} \mathrm{C}$. Após a lavagem da placa duas vezes com PBS-T e uma vez com PBS, foram adicionados $100 \mu \mathrm{L}$ substrato/ cromógeno $\left(\mathrm{H}_{2} \mathrm{O}_{2} /\right.$ Tetrametilbenzidina -TMBZ). Após incubação por quinze minutos, a reação foi bloqueada pela adição de $50 \mu \mathrm{L}$ de ácido sulfúrico $1 \mathrm{~N}$, e a absorvância foi determinada em Multi-Skan a 450nm. Como controle negativo foi utilizado um "pool" de soros de cavalos com idade variando de um a dois anos, que apresentavam absorvâncias em torno de 0,07 a 0,100 . Foram consideradas positivas, as amostras que apresentaram absorvância duas vezes maior do que a do controle negativo.

\section{Imunodifusão em gel de Agar}

Os testes de imunodifusão foram realizados conforme descrito previamente por Camargo et al. (1988) com a utilização do exoantígeno de $P$. brasiliensis como reagente.

\section{Análise estatística}

Os dados foram analisados pelo teste quiquadrado (Epi Info Versão 6,04b), sendo que a diferença foi considerada significativa quando $p \leq$ 0,05 .

\section{Resultados e Discussão}

Há poucos relatos na literatura sobre a ocorrência da paracoccidioidomicose natural em animais. Ainda não está bem definida, com exceção dos tatus, a possibilidade de algumas espécies de animais serem hospedeiros intermediários ou reservatórios de P. brasiliensis (RESTREPO; McEWEN; CASTAÑEDA, 2001).

A infecção por $P$. brasiliensis em humanos e animais domésticos e silvestres tem sido avaliada por meio de reação intradérmica (COSTA; DINIZ; FAVA NETTO, 1995; FAVA; FAVA NETTO, 1998; MOK; FAVA NETTO, 1978). A reação intradérmica embora tenha sido muito utilizada nos estudos epidemiológicos, é um método invasivo e requer uma espera de 48 a 72 horas após a inoculação do antígeno para a realização da leitura.

Por outro lado, o ensaio de ELISA tem sido utilizado com sucesso na realização do imunodiagnóstico da paracoccidioidomicose em humanos, devido às altas sensibilidade e reprodutibilidade e à rapidez na execução. Recentemente esta técnica passou a ser utilizada 
também em estudos epidemiológicos de paracoccidioidomicose em humanos (BOTTEON et al., 2002), cães (ONO et al., 2001; SILVEIRA et al., 2006), macacos (CORTE et al., 2007) e bovinos (SILVEIRA et al., 2008).

Neste estudo, a positividade de $30 \%$, observada para PCM em cavalos, foi menor que as relatadas em dois trabalhos com eqüinos do Estado de São Paulo, nos quais $64,2 \%$ e $63,8 \%$ dos animais foram reativos no teste intradérmico com antígeno polissacarídico (COSTA; DINIZ; FAVA NETTO, 1995; COSTA; FAVA NETTO, 1978). Conti-Diaz et al. (1972), por outro lado, também utilizando o antígeno polissacarídico, relataram positividade de $23 \%$ para PCM em cavalos no Uruguai. Provavelmente essas discrepâncias sejam devido ao fato de os autores terem utilizado o antígeno polissacarídico de $P$. brasiliensis, um antígeno bruto, que pode apresentar reatividade cruzada com outros patógenos e apresentar variabilidade na composição dependendo do isolado de $P$. brasiliensis utilizado na sua produção.

Um estudo soroepidemiológico de PCM em cães da Região Norte do Estado do Paraná utilizando ensaio de ELISA com gp 43 em animais de área rural, periferia e urbana, demonstrou positividade de $89,5 \%, 48,8 \%$ e $14,8 \%$, respectivamente, sugerindo que os cães infectam-se mais facilmente com $P$. brasiliensis que os cavalos, provavelmente devido ao hábito de farejar e escavar o solo, o provável habitat do fungo (ONO et al., 2001).

$\mathrm{Na}$ PCM humana a reatividade sorológica no teste de imunodifusão é indicativo de PCMdoença. Neste estudo nenhuma amostra apresentou positividade na imunodifusão sugerindo que os animais apresentavam somente PCM-infecção. Não foram observadas diferenças significativas em relação ao sexo dos animais (Tabela 1), indicando que a exposição à infecção não é dependente do sexo. Também não foi observada diferença significativa em relação à faixa etária (Tabela 1). Em estudo soroepidemiológico de paracoccidiodiomicose em cães e macacos também não foram observadas diferenças de freqüência entre os sexos (CORTE et al., 2007; ONO et al., 2001; SILVEIRA et al., 2006).

Tabela 1. Positividade sorológica para P. brasiliensis em 100 amostras de soros de cavalos da Região Norte do Estado do Paraná analisados por ELISA e Imunodifusão em gel (ID).

\begin{tabular}{|c|c|c|c|c|c|}
\hline \multirow[b]{3}{*}{ Sexo } & \multicolumn{2}{|c|}{$\begin{array}{c}\text { Positivo } \\
\text { n (\%) }\end{array}$} & \multicolumn{2}{|c|}{$\begin{array}{c}\text { Negativo } \\
\text { n (\%) }\end{array}$} & \multirow[t]{2}{*}{$\begin{array}{c}\text { Total } \\
\text { n (\%) }\end{array}$} \\
\hline & ELISA & ID & ELISA & ID & \\
\hline & & & & & \\
\hline Macho & $17(32,1)$ & $0(0)$ & $36(67,9)$ & $53(100)$ & $53(53,0)$ \\
\hline Fêmea & $13(27,7)$ & $0(0)$ & $34(72,3)$ & $47(100)$ & $47(47,0)$ \\
\hline \multicolumn{6}{|c|}{ Idade (anos) } \\
\hline $1-5$ & $9(29,0)$ & $0(0)$ & $31(71,0)$ & $40(100)$ & $40(40)$ \\
\hline $5-10$ & $21(38,2)$ & $0(0)$ & $34(61,8)$ & $55(100)$ & $55(55)$ \\
\hline$>10$ & $0(0)$ & $0(0)$ & $5(100)$ & $5(100)$ & $5(5)$ \\
\hline Total & $30(30,0)$ & $0(0)$ & $70(70,0)$ & $100(100)$ & $100(100)$ \\
\hline
\end{tabular}


Há relatos de desenvolvimento de blastomicose, causada pelo fungo Blastomyces dermatitidis, em cavalos da América do Norte (TORIBIO et al., 1999; WILSON et al., 2006). Considerando a proximidade filogenética entre os agentes etiológicos da paracoccidioidomicose e da blastomicose, é possível que o cavalo também seja susceptível ao desenvolvimento da PCM-doença, como ocorre com o cão (FARIAS et al., 2005; RICCI et al., 2004).

Os estudos soroepidemiológicos com diferentes espécies de animais domésticos e silvestres podem contribuir para a elucidação do habitat do $P$. brasiliensis.

\section{Agradecimentos}

Os autores agradecem ao $\mathrm{CNPq}$, CAPES e Fundação Araucária pela concessão de auxílio financeiro para a realização deste trabalho.

\section{Referências}

ALBORNOZ, M. B. Isolation of Paracoccidoides brasiliensis from rural soil in Venezuela. Sabouraudia, Edinburgh, v. 9, n. 3, p. 248-253, 1971.

BAGAGLI, E.; SANO, A.; COELHO, K. I.; ALQUATI, S.; MIYAJI, M.; CAMARGO, Z. P.; GOMES, G. M.; FRANCO, M.; MONTENEGRO, M. R. Isolation of Paracoccidioides brasiliensis from armadillos (Dasypus novemcinctus) captured in an endemic area of paracoccidioidomycosis. American Journal of Tropical Medicine and Hygiene, Mclean, v. 58, n. 4, p. 505-512, 1998.

BLOTTA, M. H. S. L.; CAMARGO, Z. P. Immunological response to cell-free antigens of Paracoccidioides brasiliensis: relationship with clinical forms of paracoccidioidomycosis. Journal of Clinical Microbiology, Washington, v. 31, n. 3, p. 671-676, 1993.

BORGES-WALMSLEY, M. I.; CHEN, D.; SHU, X; WALMSLEY,A.R. The pathobiology of Paracoccidioides brasiliensis. Trends in Microbiology, Cambridge, v. 10, n. 2, p. 80-87, Feb. 2002.

BOTTEON, F. A.; CAMARGO, Z. P.; BENARD, G.; COELHO, R. F.; CHAMONE, D .A.; ITANO, E. N.
Paracoccidioides brasiliensis-reactive antibodies in Brazilian blood donors. Medical Mycology, Oxford, v. 40, n. 4, p. 387-391, 2002.

BRADFORD, M. M. A rapid and sensitive method for the quantitation of microgram quantities of protein utilizing the principle of protein-dye binding. Analytical Biochemistry, New York, v. 72, n. 1-2, p. 248-254, 1976.

BRUMMER, S. O.; CASTANEDA, E.; RESTREPO, A. Paracoccidioidomycosis: an update. Clinical Microbiology Reviews, Washington, v. 6, n. 2, p. 89-117, 1993.

CAMARGO, Z. P.; UNTERKIRCHER, C.; CAMPOY, S. P.; TRAVASSOS, L. R. Production of Paracoccidioides brasiliensis exoantigens for immunodiffusion test. Journal of Clinical Microbiology, Washington, v. 26, n. 10, p. 2147-2151, 1988.

CONTI-DIAZ, I. A.; ALVAREZ, B. J.; GEZUELE, E.; GONZALEZ MARINI, H.; DUARTE, J.; FALCON, J. Intradermal reaction survey with paracoccidioidin and histoplasmin in horses. Revista do Instituto de Medicina Tropical de São Paulo, São Paulo, v. 14, n. 6, p. 372-376, 1972.

CORTE, A. C.; SVOBODA, W. K.; NAVARRO, I. T.; FREIRE, R. L.; MALANSKI, L. S.; SHIOZAWA, M. M.; LUDWIG, G.; AGUIAR, L. M.; PASSOS, F. C.; MARON, A.; CAMARGO, Z. P.; ITANO, E. N.; ONO, M. A. Paracoccidioidomycosis in wild monkeys from Paraná State, Brazil. Mycopathologia, Den Haag, v. 164, n. 5, p. 225-228, 2007.

COSTA, E. O.; DINIZ, L. S. M.; FAVA NETTO, C. The prevalence of positive intradermal reactions to paraccodioidin in domestic and wild animals in São Paulo, Brazil. Veterinary Research Communications, Amsterdam, v. 19, n. 2, p. 127-130, Mar. 1995.

COSTA, E.; FAVA NETTO, C. Paracoccidioidin and histoplasmin intradermic tests in domestics animals. Sabouraudia, Edinburgh, v. 16, n. 2, p. 103-111, 1978.

COUTINHO, Z. F.; SILVA, D.; LAZÉRA, M.; PETRI, V.; OLIVEIRA, R. M. O.; SABORZA, P. C.; WANKE, B. Paracoccidioidomycosis mortality in Brazil (19801995). Cadernos de Saúde Pública, Rio de Janeiro, v. 18, n. 5, p. 1441-1454, 2002.

FARIAS, M. R.; WERNER, J; MURO, M.; MARQUES, S. A.; MARQUES, M. E.; FRANCO, M.; RIBEIRO, M. G.; CUSTÓDIO, C. C.; CONDAS, L. A. Z.; BOSCO, S. M. G.; BAGAGLI, E. Canine Paracoccidioidomycosis: case report of generalized lymphadenitis. Revista do Instituto de Medicina Tropical de São Paulo, São Paulo, v. 47, Supl., p. 64, 2005. 
FAVA, S. C.; FAVA NETTO, C. Epidemiologic surveys of histoplasmin and paracoccidioidin sensitivity in brazil. Revista do Instituto de Medicina Tropical de São Paulo, São Paulo, v. 40, n. 3, p. 155-164, 1998.

FRANCO, M.; MONTENEGRO, M. R.; MENDES, R. P.; MARQUES, S. A.; DILLON, N. L.; MOTA, N. G. Paracoccidioidomycosis: a recently proposed classification on its clinical forms. Revista da Sociedade Brasileira de Medicina Tropical, Rio de Janeiro, v. 20, n. 2, p. 129-133, 1987.

GROSE, E.; TAMSITT, J. R. Paracoccidioides brasiliensis recovered from the intestinal tract of three bats (Artibeus lituratus) in Colombia. Sabouraudia, Edinburgh, v. 4, n. 2, p. 124-5, 1965.

LONDERO, A.; RAMOS, C. D. Paracoccidioidomycosis: a clinical and mycologic study in fourty-one cases observed in Santa Maria, RS Brazil. American Journal of Medicine, New York, v. 52, n. 6, p. 771-775, Dec. 1972.

LUTZ, A. Uma mycose pseudoccidica localizada na boca e observada no Brasil. Contribuição ao conhecimento das hyphoblastomycosis americanas. Brasil-medico, Rio de Janeiro, v. 22, n. 13, p. 121-124, 1908.

McEWEN, J. G.; GARCIA, A. M.; ORTIZ, B. L.; BOTERO, S.; RESTREPO, A. In search of the natural habitat of Paracoccidioides brasiliensis. Archives of Medical Research, México, v. 26, n. 3, p. 305-306, 1995.

MOK, W. Y.; FAVA NETTO, C. F. Paracoccidioidin and histoplasmin sensitivity in Coari (state of Amazonas), Brazil. American Journal of Tropical Medicine and Hygiene, Mclean, v. 27, n. 4, p. 808-814, 1978.

MÓS, E. N.; FAVA NETTO, C. Contribuição ao estudo da paracoccidiodomicose. I. Possível papel epidemiológico dos cães. Estudo sorológico e anatomo-patológico. Revista do Instituto de Medicina Tropical de São Paulo, São Paulo, v. 16, n. 3, p. 154-159, 1974.

NAIFF, R. D.; FERREIRA, L. C. L.; BARRETT, T. V.; NAIFF, M. F.; ARIAS, J. R. Enzootic paracoccidioidomycosis in armadillos (Dasypus novemcinctus) in the State of Pará. Revista do Instituto de Medicina Tropical de São Paulo, São Paulo, v. 28, n. 1, p. 19-27, 1986.

ONO, M. A.; BRACARENSE, A. P. F. R. L.; MORAIS, H. S. A.; TRAPP, S. M.; BELITARDO, D. R.; CAMARGO, Z. P. Canine paracoccidioidomycosis: a seroepidemiologic study. Medical Mycology, Oxford, v. 39 , n. 3, p. 277-282, 2001.
RESTREPO, A.; McEWEN, J. G.; CASTAÑEDA, E. The habitat of Paracoccidioides brasiliensis: how far from solving the riddle? Medical Mycology, Oxford, v. 39, n. 3, p. 233-241, 2001.

RICCI, G.; MOTA, F. T.; WAKAMATSU, A.; SERAFIM, R. C.; BORRA, R. C.; FRANCO, M. Canine Paracoccidioidomycosis. Medical Mycology, Oxford, v. 42, n. 4, p. 379-383, 2004.

SARAIVA, E. C.; ALTEMANI, A.; FRANCO, M. F.; UNTERKIRCHER, C. S.; CAMARGO, Z. P. Paracoccidioides brasiliensis-gp43 used as paracoccidioidin. Journal of Medical and Veterinary Mycology, Oxfordshire, v. 34, n. 3, p. 155-161, 1996.

SCULLY, C; ALMEIDA, P. Orofacial manifestations of the systemic mycoses. Journal of Oral Pathology and Medicine, Copenhagen, v. 21, n. 7-10, p. 289-294, 1992.

SILVA-VERGARA, M.L.; MARTINEZ, R.; CHADU,A.; MADEIRA, M.; FREITAS-SILVA, G.; LEITE MAFFEI, C. M. Isolation of Paracoccidioides brasiliensis strain from the soil of a coffee plantation in Ibiá, State of Minas Gerais, Brazil. Medical Mycology, Oxford, v. 36, n. 1, p. 37-42,1998.

SILVEIRA, L. H.; DOMINGOS, I. H.; KOUCHI, K.; ITANO, E. N.; SILVA, E. A.; LANDGRAF, V. O.; WERNECK, S. M.; CAMARGO, Z. P.; ONO, M. A. Serological detection of antibodies against Paracoccidioides brasiliensis in dogs with leishmaniasis. Mycopathologia, Den Haag, v. 162, n. 5, p. 325-329, 2006.

SILVEIRA, L. H.; PAES, R. C. S.; MEDEIROS, E. V.; ITANO, E. N.; CAMARGO,Z.P.; ONO, M.A. Occurrence of antibodies to Paracoccidioides brasiliensis in dairy cattle from Mato Grosso do Sul, Brazil. Mycopathologia, Den Haag, v. 165, n. 6, p. 367-371, 2008.

TORIBIO, R. E.; KOHN, C. W., LAWRENCE, A. E., HARDY, J.; HUTT, J. A. Thoracic and abdominal blastomycosis in a horse. Journal of the American Veterinary Medical Association, Schaumburg, v. 214, n. 9, p. 1357-1360, 1999.

WILSON, J. H.; OLSON, E. J.; HAUGEN, E. W.; HUNT, L. M.; JOHNSON, J. L.; HAYDEN, D. W. Systemic blastomycosis in a horse. Journal of Veterinary Diagnostic Investigation, Columbia, v. 18, n. 6, p. 615619, 2006. 